\title{
Non-surgical management of chronic periodontitis using subgingival irrigation with ozonized water- A clinical study
}

\author{
Eiti Agrawal $^{1, *}$, Preeti Sharma ${ }^{2}$, Rahul Chopra $^{3}$, Nikhil Sharma $^{4}$, Rajat Singla $^{5}$, Neelam Raghav $^{6}$ \\ 1,2,5,6 Post Graduate Student, ${ }^{3}$ Associate Professor, ${ }^{4} \mathrm{HOD},{ }^{3,4}$ Dept. of Periodontology and Implantology, I.T.S Centre for Dental
} Studies \& Research, Muradnagar, Ghaziabad, India

*Corresponding Author:

Email: dreiti.agarwal@gmail.com

\begin{abstract}
Introduction: Periodontitis is the destructive inflammatory disease of the supporting tissue of the teeth resulting in formation of periodontal pocket, gingival recession or both. Ozone $\left(\mathrm{O}_{3}\right)$ is a triatomic molecule having disinfectant, antimicrobial and healing properties and has shown promising results in the treatment of periodontitis.

The present study evaluated the usefulness of ozone water as an adjunct in non-surgical periodontal treatment.

Materials and Method: In this split mouth study, 21 sites each of periodontal pockets $(\geq 4 \mathrm{~mm})$ in patients with chronic periodontitis were randomly divided into two groups; SRP followed by irrigation with ozonated water test site and SRP followed by irrigation with distilled water (control site).The clinical parameters including plaque index, gingival index, periodontal probing depth and clinical attachment level (CAL) were recorded at baseline and 4 weeks recall.

Result: Both the groups (test \& control) showed improvement in all the recorded parameters (PI, GI, CAL, PPD) while the test group showed statistically significant reduction in all the clinical parameters compared to control group $(\mathrm{p}<0.05)$.

Conclusion: A single subgingival irrigation with ozonated water can be effectively used as an adjunct to SRP in non-surgical management of chronic periodontitis.
\end{abstract}

Keywords: Chronic periodontitis, scaling, root planing, subgingival irrigation, ozone water, non-surgical therapy.

\section{Introduction}

Chronic periodontitis is an inflammatory multifactorial disease resulting in destruction of the alveolar bone and connective tissues of the gingiva and periodontal ligament. ${ }^{1}$ The primary etiological agents, however, are the pathogenic bacteria that colonize the dentogingival interface leading to gingivitis (Loe et al, 1965). These bacteria further cause the formation of periodontal pockets by conversion of junctional and sulcular epithelium to pocket epithelium. Dental plaque consists of diverse community of micro-organisms which is found on the tooth surface as a biofilm consisting of numerous species, embedded in an extracellular matrix of polymers of host and microbial origin. ${ }^{2}$ Removal of both supragingival and subgingival plaque is necessary for effective periodontal therapy.

Mechanical instrumentation namely scaling and root planing (SRP) remains a major phase in the treatment of periodontal diseases; however, variations in its efficacy to gain access into deep pockets, furcations or any other root morphologic alterations can leave residual plaque deposits in the pocket which can result in the recolonization of the treated areas with pathogenic organisms. Thus, use of adjunctive systemic and local anti-microbials in addition to SRP has been advocated to further reduce/eliminate micro-organisms count more specifically. Long term use of systemic anti-microbials is not recommended because of chances of development of bacterial resistance and other associated side effects. Local administration of antimicrobial agents offers a "site-specific" approach to the periodontal therapy having several benefits; primarily, it is localized to the infected sites at high concentrations avoiding potentially adverse reactions inherent to the systemic use of these medications. ${ }^{3}$

One of the methods for local administration of antimicrobial agent is subgingival irrigation which can be described as intentional irrigation of a gingival crevice or pocket where the point of delivery directed below the gingival margin can be done by various antimicrobial agents such as Chlorhexidine, a mixture of sodium bicarbonate-sodium chloride, hydrogen peroxide, stannous fluoride, Boric acid and Tetracycline. ${ }^{4}$ Despite showing promising results, these existing antiseptic agents have several shortcomings. Hence, there is constant search for a better alternative.

Ozone $\left(\mathrm{O}_{3}\right)$, an allotropic molecule of the chemical oxygen element has been used as one of the nonmedication methods of treatment in medical field for a long time. The term ozone, originates from the Greek word ozein, which means odor or send smell. The German chemist Christian Friedrich Schonbein known as "the father of ozone therapy" first used it in $1840^{5}$ and the first dentist to use ozone therapy in his practice was E. A. Fisch in $1930 .{ }^{6}$ Although it is an unstable gas that quickly gives up nascent oxygen radical to form oxygen gas, it is also a powerful oxidizer. Due to the property of releasing nascent oxygen, it has been used in human medicine for a long time to kill bacteria, fungi, inactivate viruses and to control hemorrhages. ${ }^{7}$ It is having a wide range of antimicrobial, immunostimulatory, antihypoxic, bioenergetic, and biosynthetic action. ${ }^{8}$ 
Numerous studies have been conducted in the past that proved its successful application in almost each branch of dentistry. Its various dental applications include removal/inactivation of oral pathogens, treatment of dental caries, hypersensitive teeth, periapical infections, mucosal lesions, replantation of avulsed tooth, ${ }^{8}$ bleaching ${ }^{9}$ etc. It can be successfully used in cases of wound healing impairments following surgical interventions like tooth extractions or implant dentistry. Ozone can be used in four ways in the dental field as gas, ozonized water, ozonized oil, ozonized air. Among all these usages, ozonized water (aqueous form) is the most common in periodontal therapy. ${ }^{10}$ Few studies have also reported contradictory findings. ${ }^{11}$ Hence, subgingival irrigation with ozonized water in periodontal pockets along with scaling and root planing in chronic periodontitis needs to be evaluated further. The present study evaluates the use of single ozonized water subgingival irrigation as an adjunct to scaling and root planing.

\section{Materials and Methods}

Forty-two patients attending the OPD of the Department of Periodontics, I.T.S CDSR, Muradnagar were screened for this split-mouth randomized controlled clinical trial. The patients (age group $18-50$ years) diagnosed with chronic periodontitis having periodontal probing depth $\geq 4 \mathrm{~mm}$ and minimum one periodontal pocket on both the contralateral sides were selected. They had no history of systemic disease that may affect periodontium, were non-smokers with at least 20 natural teeth; and had not undergone any periodontal treatment in the last 6 months. Pregnant women and those with a history of systemic antibiotic administration within 3 months prior to the study were excluded. Those who met the inclusion criteria were considered for the treatment and follow-up.

Fourteen patients met the inclusion criteria and all agreed to enroll in the study and signed the informed consent form. Ethical approval was obtained from the institutional ethical committee. Complete history was taken and comprehensive periodontal examination was performed at baseline. Total 48 periodontal pocket sites were selected in eligible subjects and randomly assigned into one of two groups ( 24 periodontal pocket sites each contralaterally): Group 1 (Control group) that received single subgingival irrigation with distilled water after SRP and Group 2 (Test group) that received single subgingival irrigation with ozone water after SRP were included.

Two different examiners conducted the study. The first examiner was the clinical operator and conducted each type of treatment. The second examiner recorded the data and was blinded to the treatment received by patients. The clinical parameters like Gingival index
(Loe and Silness), ${ }^{12}$ Turesky-Gilmore-Glickman Modification of Quigley Hein plaque index, ${ }^{13}$ Periodontal probing depth (measured using a UNC 15 probe), clinical attachment levels were recorded and SRP was done using ultrasonic scalers (Suprasson Newtron) and Gracey curettes (Hu-Friedy) until the root surfaces felt smooth and hard to tactile exploration.

Preparation of aqueous ozone was done by treating distilled water with gaseous ozone by using an ozone generator (ozonizer; LS F9) having $400 \mathrm{mg} / \mathrm{hr}$ output. ${ }^{14}$ In the end of the non-surgical treatment visit, the periodontal pocket site was irrigated by a blunt-tipped sterile plastic syringe containing ozonated water (in the test group) or distilled water (in the control group).The tip of the syringe was inserted $3 \mathrm{~mm}$ deep into the pocket and the pocket was irrigated for one minute. Patient was told not to eat and drink anything for 30 minutes. Oral hygiene instructions were given to all patients.

After 4 weeks, patients were reviewed and clinical parameters were again recorded. Two subjects were lost during follow-up, leaving 12 subjects with 21 periodontal pocket sites each contralaterally. Patients who were lost during follow-up were not included in the baseline and follow-up statistical analysis. (Fig. 1)

\section{Statistical analysis}

The Statistical Analysis Software (SPSS version 16) was used for data processing and analysis. The differences in means of the parameters at the baseline between test and control groups were evaluated using an independent t-test. The changes in parameters over time were evaluated using a paired $\mathrm{t}$-test for each group separately, $\mathrm{p}<0.05$ was considered statistically significant.

\section{Result}

In this randomized controlled clinical trial, both the groups (test \& control) showed improvement in all the recorded parameters (PI, GI, CAL, PPD).None of the treated patient reported with any adverse effect following periodontal therapy.

In control group PI, GI, PPD, \& CAL significantly reduced after 4 weeks follow-up compared to baseline (Table 1). Similarly, PI, GI, PPD \& CAL significantly reduced in Test group also after 4 weeks follow-up compared to baseline (Table 2).

On inter group comparison between test \& control group, there was no statistically significant difference amongst the clinical parameters (PI, GI, PPD, \& CAL) at baseline. However, after 4 weeks follow-up the test group showed statistically significant improvement in recorded parameters compared to control group (Table $3)$. 


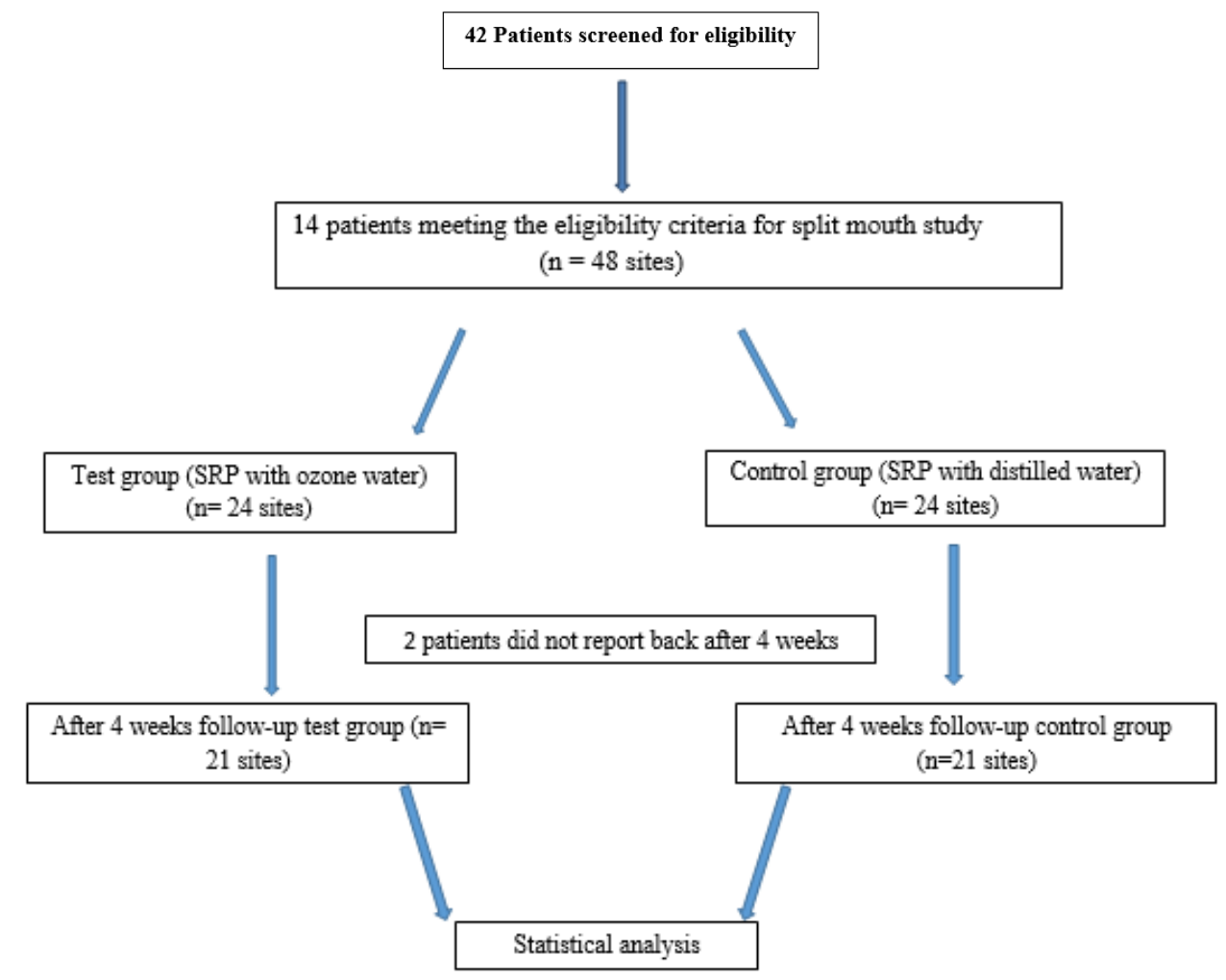

Fig. 1: Flow Chart showing study design

Table 1: Intra Group Comparision of Clinical Parameters (Test Group)

\begin{tabular}{|c|l|c|c|c|c|c|}
\hline \multicolumn{7}{|c|}{ Paired Samples Statistics } \\
\hline & & $\mathbf{N}$ & \multicolumn{2}{|c|}{$\begin{array}{c}\text { Mean } \pm \text { std. } \\
\text { Deviation }\end{array}$} & $\begin{array}{c}\text { Std. Error } \\
\text { Mean }\end{array}$ & p value \\
\hline \multirow{2}{*}{ Pair 1 } & CAL Baseline & 21 & 5.35 & \pm .875 & 0.196 & \multirow{2}{*}{.001} \\
\cline { 2 - 7 } & CAL 1 Month & 21 & 3.3 & \pm .733 & 0.164 & \\
\hline \multirow{2}{*}{ Pair 2 } & GI Baseline & 21 & 1.8 & \pm .410 & 0.092 & \multirow{2}{*}{.001} \\
\cline { 2 - 7 } & GI 1 Month & 21 & 0.65 & \pm .489 & 0.109 & \\
\hline Pair 3 & PPD Baseline & 21 & 4.9 & \pm .788 & 0.176 & \multirow{2}{*}{.001} \\
\cline { 2 - 6 } & PPD 1 Month & 21 & 2.9 & \pm .641 & 0.143 & \\
\hline Pair 4 & PI Baseline & 21 & 1.5 & \pm .513 & 0.115 & \multirow{2}{*}{.001} \\
\cline { 2 - 6 } & PI 1 Month & 21 & 0.65 & \pm .587 & 0.131 & \\
\hline
\end{tabular}

Table 2: Intra Group Comparision of Clinical Parameters (Control Group)

\begin{tabular}{|l|l|c|c|c|c|c|}
\hline & & $\mathbf{N}$ & \multicolumn{2}{|c|}{$\begin{array}{c}\text { Mean } \pm \text { std. } \\
\text { Deviation }\end{array}$} & $\begin{array}{c}\text { Std. Error } \\
\text { Mean }\end{array}$ & p value \\
\hline \multirow{2}{*}{ Pair 1 } & CAL Baseline & 21 & 5.15 & \pm .875 & 0.196 & \multirow{2}{*}{.001} \\
\cline { 2 - 6 } & CAL 1 Month & 21 & 4.35 & \pm .587 & 0.131 & \\
\hline \multirow{2}{*}{ Pair 2 } & GI Baseline & 21 & 1.85 & \pm .366 & 0.082 & \multirow{2}{*}{.001} \\
\cline { 2 - 6 } & GI 1Month & 21 & 1.3 & \pm .470 & 0.105 & \\
\hline \multirow{2}{*}{ Pair 3 } & PPD Baseline & 21 & 4.55 & \pm .510 & 0.114 & \multirow{2}{*}{.001} \\
\cline { 2 - 6 } & PPD 1 Month & 21 & 4.1 & \pm .553 & 0.124 & \\
\hline Pair 4 & PI Baseline & 21 & 1.35 & \pm .489 & 0.109 & \multirow{2}{*}{.001} \\
\cline { 2 - 6 } & PI 1 Month & 21 & 1.05 & \pm .394 & 0.088 & \\
\hline
\end{tabular}


Table 3: Inter group comparison of clinical parameters between test \& control group

\begin{tabular}{|c|c|c|c|c|c|c|c|}
\hline \multirow{3}{*}{$\begin{array}{l} \\
\text { CAL } \\
\text { Baseline }\end{array}$} & \multirow{2}{*}{$\begin{array}{l}\text { Group } \\
\text { Control }\end{array}$} & \multirow{2}{*}{$\begin{array}{l}\mathbf{N} \\
21\end{array}$} & \multicolumn{2}{|c|}{$\begin{array}{c}\text { Mean } \\
\pm \text { Std. } \\
\text { Deviation }\end{array}$} & \multicolumn{2}{|c|}{$\begin{array}{c}\text { Mean Difference } \\
\pm \text { Std. Error } \\
\text { Mean }\end{array}$} & \multirow{3}{*}{$\begin{array}{c}\begin{array}{c}\mathbf{p} \\
\text { value }\end{array} \\
.474\end{array}$} \\
\hline & & & 5.15 & \pm .875 & \multirow[t]{2}{*}{-.200} & \multirow[t]{2}{*}{ \pm .196} & \\
\hline & Test & 21 & 5.35 & \pm .875 & & & \\
\hline \multirow{2}{*}{$\begin{array}{l}\text { CAL 1 } \\
\text { Month }\end{array}$} & Control & 21 & 4.35 & \pm .587 & \multirow[t]{2}{*}{-.450} & \multirow[t]{2}{*}{ \pm .131} & \multirow[t]{2}{*}{.001} \\
\hline & Test & 21 & 3.30 & \pm .733 & & & \\
\hline \multirow{2}{*}{$\begin{array}{l}\text { PI } \\
\text { Baseline }\end{array}$} & Control & 21 & 1.35 & \pm .503 & \multirow[t]{2}{*}{.400} & \multirow[t]{2}{*}{ \pm .112} & \multirow[t]{2}{*}{.350} \\
\hline & Test & 21 & 1.50 & \pm .366 & & & \\
\hline \multirow{2}{*}{$\begin{array}{l}\text { PI 1 } \\
\text { Month }\end{array}$} & Control & 21 & 1.05 & \pm .394 & \multirow[t]{2}{*}{.050} & \multirow[t]{2}{*}{ \pm .088} & \multirow[t]{2}{*}{.016} \\
\hline & Test & 21 & .65 & \pm .587 & & & \\
\hline \multirow{2}{*}{$\begin{array}{l}\text { GI } \\
\text { Baseline }\end{array}$} & Control & 21 & 1.85 & \pm .366 & \multirow[t]{2}{*}{.650} & \multirow[t]{2}{*}{ \pm .082} & \multirow[t]{2}{*}{.687} \\
\hline & Test & 21 & 1.80 & \pm .410 & & & \\
\hline \multirow{2}{*}{$\begin{array}{l}\text { GI } 1 \\
\text { Month }\end{array}$} & Control & 21 & 1.30 & \pm .470 & \multirow[t]{2}{*}{-.350} & \multirow[t]{2}{*}{ \pm .105} & \multirow[t]{2}{*}{.001} \\
\hline & Test & 21 & .65 & \pm .489 & & & \\
\hline \multirow{2}{*}{$\begin{array}{l}\text { PPD } \\
\text { Baseline }\end{array}$} & Control & 21 & 4.55 & \pm .510 & \multirow[t]{2}{*}{-.200} & \multirow[t]{2}{*}{ \pm .114} & \multirow[t]{2}{*}{.104} \\
\hline & Test & 21 & 4.90 & \pm .788 & & & \\
\hline \multirow{2}{*}{$\begin{array}{l}\text { PPD 1 } \\
\text { Month }\end{array}$} & Control & 21 & 4.10 & \pm .553 & \multirow[t]{2}{*}{-.450} & \multirow[t]{2}{*}{ \pm .124} & \multirow[t]{2}{*}{.001} \\
\hline & Test & 21 & 2.90 & \pm .641 & & & \\
\hline
\end{tabular}

\section{Discussion}

Plaque and calculus are considered as major etiological factors for gingivitis and periodontitis. Plaque biofilm removal or control is mandatory for any therapeutic periodontal procedure. It is primarily achieved by non-surgical periodontal therapy i.e. scaling and root planing (SRP) that results in the healing and improvement of periodontal pocket depth by decreasing inflammation and also by the ability to form thin junctional epithelium since the contaminated cementum layer has been removed ${ }^{15}$. However, many a times mechanical therapy alone may not be effective, hence adjunctive use of antimicrobials has been proposed and one such agent is ozone. The use of ozone in dental therapy has gained popularity mainly due to its antioxidant properties damaging microbial cells but not the human body cells. ${ }^{16}$

In this, split mouth study, SRP was performed followed by subgingival irrigation using ozone (test group) and distilled water (control group). In both the groups, improvements in clinical parameters (PI, GI, PPD and CAL) were seen at 4 weeks follow-up. Similar results have been reported in previous studies by Ramzy et al ${ }^{15}$ and Issac et al. ${ }^{17}$ This could be attributed to the fact that patients have undergone treatment with SRP which has effectively removed plaque and calculus in both the groups, in agreement with a previous study. ${ }^{18}$

In our study, aqueous form of ozone was used for subgingival irrigation in test group which resulted in statistically significant improvement in GI and PI compared to control group. Irrigation by ozone after SRP has been studied in various studies previously like Ramzy et $\mathrm{al}^{15}$ and Dodwad et $\mathrm{al}^{19}$ who concluded substantial reduction in GI and PI after 4 weeks of subgingival ozone irrigation. Similar results were reported by Issac et a ${ }^{17}$ and Katti et al. ${ }^{20}$ In a study by Kshitish and Laxman ${ }^{21}$ who compared irrigation with ozone and $0.2 \%$ chlorhexidine and found considerable reduction in plaque index and gingival index in ozone group. In the present study irrigation with ozone would have disrupted microbial envelope through lipid peroxidation resulting in significant reduction in all clinical parameters from baseline to 4 weeks when compared to control group. Also, ozone irrigation has role in decreasing inflammatory mediators by changing plaque composition. ${ }^{22}$ The reinforcement of oral hygiene instructions and patient compliance added to the efficacy of the therapy. In contrast, Pandya et $\mathrm{al}^{23}$ compared chlorhexidine with ozone water and concluded that chlorhexidine had a slight edge over ozonated water in terms of efficacy.

The significant reduction in PPD and CAL gain in test group seen in the present study, were similar to studies done by Issac et $\mathrm{al}^{17}$ and Chaudhari et $\mathrm{al}^{24}$ who reported reduction in probing depth and increase in clinical attachment following ozone irrigation at 4 weeks and 3 weeks respectively. Further, Katti et $\mathrm{al}^{20}$ studying clinical effects of ozonated water on periodontal tissues found that it was more effective in achieving clinical attachment gain on mesial and distal site when compared with irrigation with saline. This can be attributed to the site-specific action of ozonated water as it can show both direct reactions of molecular ozone as well as a free radical-mediated reaction on periodontal tissues. ${ }^{25}$ Ozone owing to its oxygenating properties can also result in suppression of anaerobic microorganisms thus causing shift in microbial species in plaque biofilm. ${ }^{17}$ It can also serve as a good tool during supportive periodontal therapy especially in cases where surgical therapy is not possible. 
The results of above mentioned studies conducted on patients with chronic and aggressive periodontitis agree with the findings of the present study. However, Habashneh et al in $2014^{11}$ conducted similar study and concluded that ozone has improved the condition but there was no statistically significant benefit compared to SRP alone. It may be explained in terms of duration of the study as it was a 3 months study.

The strength of the present study was blinding of operators as well as negligible increase in chairside time. However, ozone has certain limitations like the stability in water is low and it decays quickly at roomtemperature within 5 mins. ${ }^{26,27}$ This might reduce the efficacy of ozonated water irrigation. Hence, to overcome this, in the present study, irrigation was done immediately following preparation of ozonated water. Also, microbiological analysis would have added further strength to the present study. A 4-week analysis of single ozone irrigation was found to be effective in the present study but to evaluate the long-term effects of this modality as a useful adjunct to mechanical instrumentation, long-term studies along with microbiological assessment are further needed.

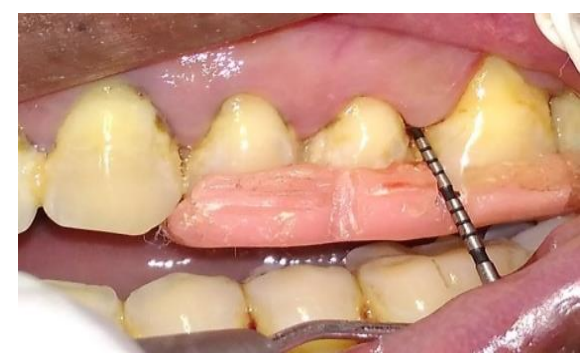

Fig. 1: Pre-operative measurement of pocket probing depth

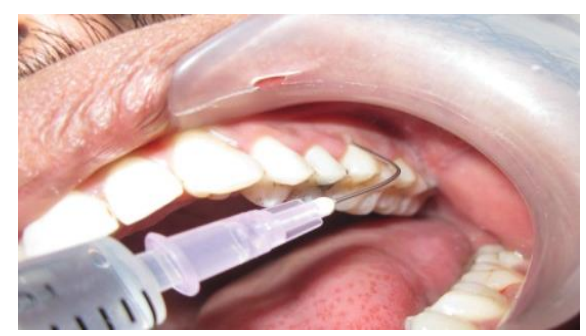

Fig. 2: Ozone irrigation

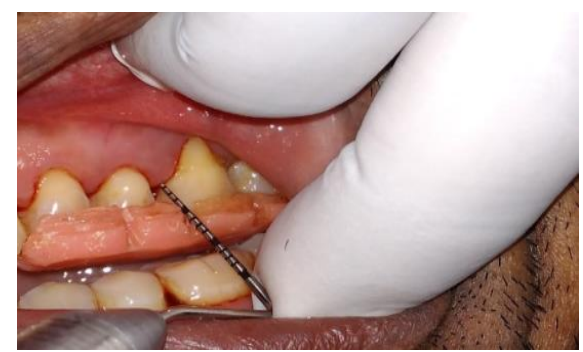

Fig. 3: Measurement of pocket probing depth after 4 weeks

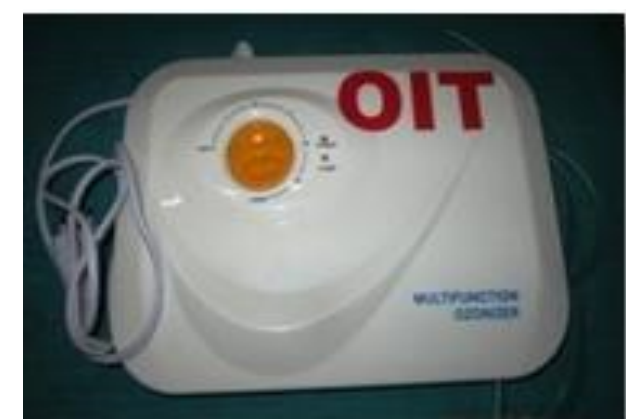

Fig. 4: Ozone generator (ozonizer; LS F9)

\section{Conclusion}

Within the limitations of this study it can be concluded that single irrigation with ozonated water was effective in decreasing inflammation, pocket depth as well as increasing clinical attachment level in chronic periodontitis patients and can be successfully used as an adjunct to SRP in routine non-surgical periodontal therapy.

Financial or other competing interests: None

\section{References}

1. Page RC, Kornman KS. The pathogenesis of human periodontitis: An introduction. Periodontol 2000 1997;14:9-11.

2. Marsh PD. Dental Plaque as a Microbial Biofilm. Caries Res 2004; 38:204-11.

3. Goodman $\mathrm{CH}$, Robinson PJ. Periodontal Therapy: Reviewing Subgingival Irrigations and Future

Considerations. J Am Dent Assoc 1990;121:541-3.

4. Wennström JL, Heijl L, Dahlén G, Gröndahl K. Periodic subgingival antimicrobial irrigation of periodontal pockets. J Clin Periodontol 1987;14:541-50.

5. Seidler V, Linetskiy I, Hubalkova H, Stankova H, Smucler R, Mazanek J. Ozone and its usage in general medicine and dentistry. Prague Med Rep 2008;109(1):513.

6. Bayson A, Lynch E. Antimicrobial effects of ozone on caries. In: Lynch E, editor. Ozone: the revolution in dentistry. London Quintessence Publishing Co.; 2004. p. 165-72.

7. Srikanth A, Sathish M, Sri Harsha AV. Application of ozone in the treatment of periodontal disease. J Pharm Bioallied Sci 2013;5:S89-94.

8. Tiwari S, Avinash A, Katiyar S, Aarthi Iyer A, Jain S. Dental applications of ozone therapy: A review of literature. Saudi J Dent Res 2017;8:105-11.

9. Ebensberger U, Pohl Y, Filippi A. PCNA-expression of cementoblasts and fibroblasts on the root surface after extraoral rinsing for decontamination. Dent Traumatol 2002;18:262-6.

10. Babando P. Ozone therapy in dentistry: clinical experiences. Ozone Ther 2017;2:26-32.

11. Al Habashneh R, Alsalman W, Khader Y. Ozone as an adjunct to conventional nonsurgical therapy in chronic periodontitis: A randomized controlled clinical trial. J Periodont Res 2015;50:37-43.

12. Loe H, Silness. Periodontal disease in pregnancy. Acta Odontol Scand1963;21:533-51. 
13. Turskey S, Gilmore ND, Glickman I. Reduced plaque formation by the chloromethyl analogue of vitamin C. J Periodontol 1970;41(1):41-3.

14. Sadatullah $\mathrm{S}$. The antimicrobial effect of $0.1 \mathrm{ppm}$ ozonated water on 24-hour plaque microorganisms in situ. Braz Oral Res 2012;26:126-31.

15. Ramzy M, Gomaa H, Mostafa M, Zaki B. Management of aggressive periodontitis using ozonized water. Egypt Med J N R C 2005;6:229-45.

16. Teresa B, Wolanska E, Cieszko-Buk M, Orlowski M, Chalas R. Practical use of ozone in dentistry Comments. Ann Univ Mariae Curie Sklodowska Lubin Polonia 2008;63:28.

17. Issac, AV, Mathew, JJ, Ambooken M, Kachappilly, AJ, Ajithkumar PK, Johny T, Samuel A. Management of Chronic Periodontitis Using Subgingival Irrigation of Ozonized Water: A Clinical and Microbiological Study. J Clin Diagn Res 2015;9(8):29-33

18. Cobb CM. Clinical significance of non-surgical periodontal therapy: an evidence-based perspective of scaling and root planing. J Clin Periodontol 2002;29:2232.

19. Dodwad V, Gupta S, Sethi M, Kumar K, Masamatti S. Changing paradigm in pocket therapy-Ozone versus Conventional irrigation. Int J Public Health Dent 2011;2:7-12.

20. Katti SS, Chava VK. Effect of Ozonised water on Chronic Periodontitis - A Clinical Study. J Int Oral Health 2013;5:79-84.

21. Kshitish D, Laxman V. The use of ozonated water and $0.2 \%$ chlorhexidine in the treatment of periodontitis patients: A clinical and microbiologic study. Indian J Dent Res 2010;21:341-8.

22. Parkar S, Shah K, Darjee N, Sharma A. Efficacy of ozonated water and chlorhexidine mouth rinse against plaque and gingivitis: A randomized clinical trial. J Clin Sci 2017;14:81-5.

23. Pandya D, Manohar B, Mathur L, Shankarapillai R. Comparative evaluation of two subgingival irrigating solutions in the management of periodontal disease: A clinicomicrobial study. J Indian Soc Periodontol 2016;20:597-602.

24. Chaudhari S, Patil V, Mali R, Mali A, Patil P, Lele P. Comparative evaluation of ozone therapy as an adjunct to scaling and root planing with scaling and root planing alone in cases of chronic Periodontitis- a clinical and microbiological study. Int J Curr Med Pharm Res 2016;2:539-43.

25. Staehelin J, Hoigne J. Decomposition of ozone in water in the presence of organic solutes acting as promoters and inhibitors of radical chain reactions. Environ Sci Technol 1985;19:1206-13.

26. Wilson M. Susceptibility of oral bacterial biofilms to antimicrobial agents. J Med Microbiol 1996;44:79-87.

27. Shechter H. Spectrophotometric method for determination of ozone in aqueous solutions. Water Res 1973;7:729-39. 